
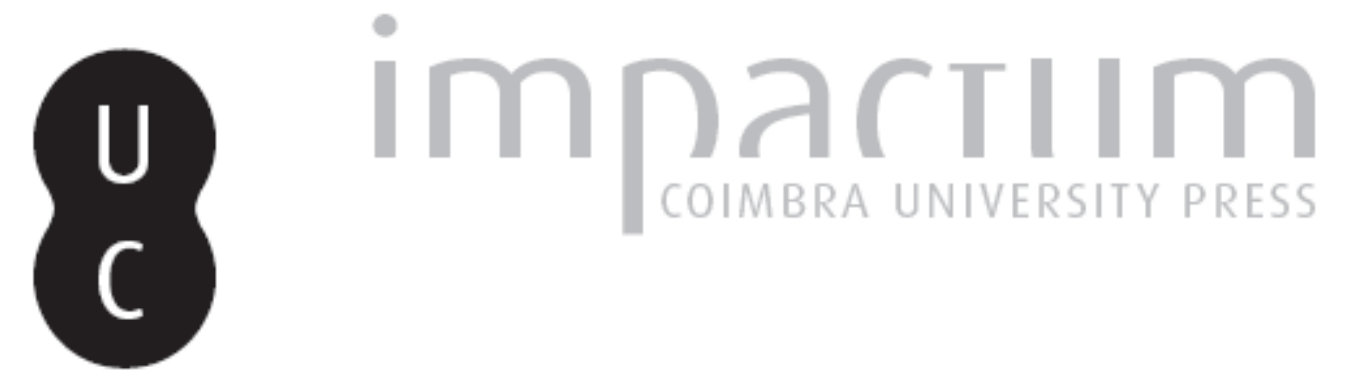

\title{
Funções estruturantes de algumas Villae pós-romanas
}

\author{
Autor(es): Man, Adriaan de
}

Publicado por: Centro de História da Universidade de Lisboa

URL persistente:

URI:http://hdl.handle.net/10316.2/23787

DOI:

DOI:http://dx.doi.org/10.14195/0871-9527_19_10

Accessed : $\quad$ 26-Apr-2023 00:58:19

A navegação consulta e descarregamento dos títulos inseridos nas Bibliotecas Digitais UC Digitalis, UC Pombalina e UC Impactum, pressupõem a aceitação plena e sem reservas dos Termos e Condições de Uso destas Bibliotecas Digitais, disponíveis em https://digitalis.uc.pt/pt-pt/termos.

Conforme exposto nos referidos Termos e Condições de Uso, o descarregamento de títulos de acesso restrito requer uma licença válida de autorização devendo o utilizador aceder ao(s) documento(s) a partir de um endereço de IP da instituição detentora da supramencionada licença.

Ao utilizador é apenas permitido o descarregamento para uso pessoal, pelo que o emprego do(s) título(s) descarregado(s) para outro fim, designadamente comercial, carece de autorização do respetivo autor ou editor da obra.

Na medida em que todas as obras da UC Digitalis se encontram protegidas pelo Código do Direito de Autor e Direitos Conexos e demais legislação aplicável, toda a cópia, parcial ou total, deste documento, nos casos em que é legalmente admitida, deverá conter ou fazer-se acompanhar por este aviso.

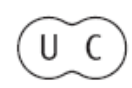



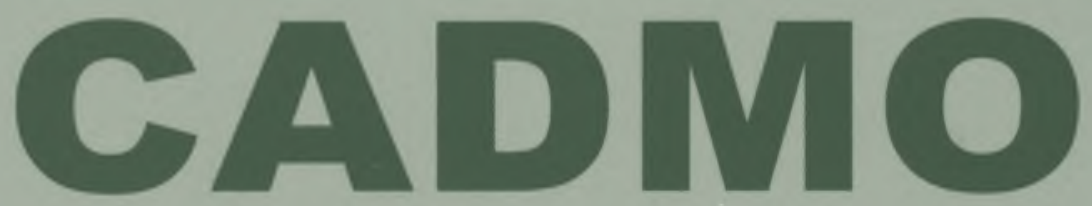

Revista de História Antiga

\author{
Centro de História \\ da Universidade de Lisboa
}

19

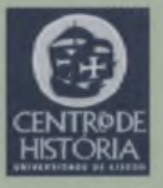

430 =

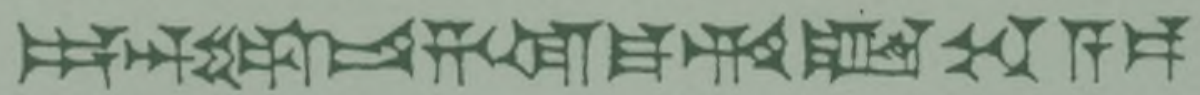

MHNIN AEI $\Delta$ E $\Theta E A ~ \Pi H \Lambda H I A \triangle E \Omega$ 


\title{
FUNÇÕES ESTRUTURANTES \\ DE ALGUMAS VILLAE PÓS-ROMANAS
}

\author{
ADRIAAN DE MAN \\ Universidade de Lisboa, ISLA - Lisboa \\ ademan@hotmail.com
}

\section{Resumo}

Existe hoje um fiável conjunto de dados que comprova transformações severas na organização rural da Antiguidade Tardia. Neste âmbito, todavia, é também questionável se a estrutura produtiva lusitana se terá desagregado através de factores homogéneos. Algumas das villae podem ter mantido ou adquirido valências de segurança, logística, fiscalidade e, acima de tudo, de formas de exploração do território.

Palavras-chave: Organização rural; Antiguidade tardia; Lusitânia; villae pós-romanas.

\section{Abstract}

A current and reliable set of data points toward severe transformations in the rural organization during Late Antiquity. However, it is also questionable if the Lusitanian productive structure disaggregated according to homogeneous factors. Some of the villae may have maintained or gained importance in logistical, fiscal and security matters and, above all, in land exploitation.

Key-words: Rural organization; Late Antiquity; Lusitania; post-roman villae. 
No processo de interpretação da paisagem antiga, e das suas evoluções em direcção ao mundo medieval, um tópico central recorrente é o do fim das villae enquanto centros orientadores do funcionamento rural. Esta discussão liga-se, por um lado, a cenários de ruptura precoce e, por outro, a uma transformação mais lenta e adaptativa. Aponte-se que boa parte das considerações sobre o assunto se vê refém de supostas homogeneidades historiográficas, em particular sobre o fim da influência imperial romana ${ }^{(1)}$, e os relatos da época em questão são amiúde tomados à letra. Sobre a utilização de fontes tardo-antigas, elas emanam de contextos específicos e de códigos de transmissão culturais e retóricos muito diferentes entre si. Um problema decorrente reside na própria qualidade dessa informação, que no confronto entre dados escritos e arqueológicos, cujos canais não são necessariamente independentes do ponto vista epistémico ${ }^{(2)}$, isto é, sobre uma mesma matéria baseiam-se sucessivamente em realidades tidas como semelhantes, embora sem realmente constituírem argumentos autónomos, e com resultados potencialmente distintos.

Noutro plano de registo, são também muito grandes as reservas ao estabelecimento de padrões incompletos ou mesmo fundamentalmente incorrectos que, transformados em informação cartográfica, produzem um resultado necessariamente distorcido. O maior caveat ao estabelecimento destes mapeamentos é, de novo, a qualidade das suas premissas. Não é a primeira ocasião em que se aponta esta fragilidade, inerente à equiparação de sítios escavados a locais com presença superficial de uma tegula fragmentada. Na consciência destas lacunas, que impossibilitam uma sistematização, este ensaio pretende chamar a atençao para a funcionalidade de núcleos agrícolas romanos num enquadramento visigótico avançado, de teor produtivo e fiscal, desligando-os de uma sobrevalorizada componente religiosa, muitas vezes tida como elemento radical.

A persistência pelo menos ocasional de domínios associáveis a villae na estruturação do território pós-romano pode ser inferida no paroquial suevo, seja directamente através dos próprios centros (Marciliana, villa Gomedei), seja pela pelos respectivos fundi: Carisiano, Curmiano ou Cantabriano ${ }^{(3)}$. Este último topónimo, situado na diocese de Lamego, importa em particular pela sua óbvia ligação à família dos Cantabri conimbrigenses referidos na Crónica de Idácio a propósito da suposta aniquilação da cidade, reflectindo não apenas alguma dispersão geográfica, mas acima de tudo uma permanência fundiária estrutural em zonas do Noroeste peninsular. De modo análogo, numa pers- 
pectiva arqueológica, não surpeendem as continuidades materiais numa multiplicidade de núcleos romanos, embora tal presença não faça inferir directamente que se continue a tratar de um centro de exploração coerente. $\mathrm{O}$ assunto da sobrevivência de estruturas de exploração em direcção à Alta Idade Média continua polémico, precisamente por representar um fenómeno de difícil documentação. Aceita se de bom grado a lógica segundo a qual muitas villae visigóticas já não seriam domínios aristocráticos mas simplesmente "aldeias»(4). Mas para um conjunto de outros sítios, a adaptação de villae em lugares centrais de cronologia visigótica não é resumível numa mera óptica de manutenção residual. Esta perspectiva é hoje globalmente aceite para os centros urbanos tardo-antigos do Ocidente, reconhecidos enquanto pólos com uma identidade própria, em vez de reduzidas sobrevivências desafectadas de um estímulo imperial. Não cabe aqui desenvolver esta ideia, mas sim valorizá-la no âmbito de uma integrada rede económica, da qual os núcleos rurais são elementos estruturantes. Deve ser tido em conta que o povoamento extra-urbano também se orientou de acordo com princípios de validação geográfica, difíceis de apreender no âmbito de modelos interpretativos lineares, e não necessariamente cristalizáveis naquele dualismo clássico, pliniano, que costuma ser critério. A este respeito, atente-se ao redutor chavão historiográfico que pretende uma desafectação das villae tardias às cidades, numa suposta renúncia das elites, deixando desse modo de injectar energia cívica nas capitais regionais. É verdade que a legislação do século IV restringe com bastante insistência a iniciativa do poder local (cf. Livro XV do Código de Teodósio), e que as villae coevas passaram a revestir-se de outras valências que não haviam tido com anterioridade. Mas uma boa parte das cidades visigóticas, tal como um certo número dos sítios rurais, manteve necessariamente em funções um esquema de centralidade das primeiras, em termos securitários, fiscais e económicos.

Outra reticência tem a ver com a relação muito ténue entre a vigência de um poder político e a gerência de sistemas produtivos regionais numa sociedade pré-industrial. Mesmo no contexto alargado dos circuitos de importação mediterrânica não se vislumbram factores absolutos, relacionáveis com súbitos câmbios de poder, e mesmo assim as tendências fazem-se sentir aparentemente mais nos centros de produção do que nos de recepção. Um exemplo clássico é o decréscimo na importação hispânica de cerâmica norte-africana sob domínio vândalo, tratando-se no entanto de um problema específico e contextual, 
aliás sem sérias continuidades, mesmo durante a oposição visigótica e bizantina. Este enquadramento de grande escala não consegue, porém, representar um argumento excessivamente optimista, e a crescente regionalização da produção e do comércio lusitano é um facto incontornável, bastando para isso contrastar a proporção entre a cerâmica local e a de importação, por um lado, e por outro as importações alto-imperiais hispânicas com as dos séculos $\mathrm{V}$ e $\mathrm{Vl}^{(5)}$, em contextos urbano e rurais.

Para o que interessa de momento, retenha-se que a valência de centros com razoável dimensão em torno das cidades não encontra, pelo menos, uma insustentabilidade teórica no período visigótico. Mesmo os avanços e recuos militares do século $V$ centraram-se sempre no controlo urbano, e não especialmente no campo, na medida em que convinha a todas as partes um funcionamento eficaz da tributação, que em qualquer dos casos teria de convergir na cidade (cf. erogatores annonae visigóticos). A clássica concepção do retalho indiscriminado dos domínios hispano-visigóticos por tertia Romanorum que, a ter ocorrido, teria de facto provocado um colapso do sistema produtivo, já não colhe os mesmos argumentos. Surge como muito improvável a súbita intromissão de elementos germânicos nesse sistema, para além de uma nova nova condição tributária( ${ }^{(6)}$. É hoje claro, pela via do direito bárbaro comparado, que a figura de tertia Romanorum reflecte uma obrigação fiscal, e que a exploração continuava integralmente em mãos hispano-romanas ${ }^{(7)}$. Esta perspectiva surge reforçada através de elementos locais avulsos, entre os quais as célebres tabuletas de Albertini são dos mais interessantes, por documentarem procedimentos legais $\operatorname{concretos}^{(8)}$ muito surpeendentes na economia agrícola do modesto fundus Tuletianos romano-vândalo ${ }^{(9)}$. Em termos estruturantes, será legítimo considerar o significado regional duradouro e específico dos centros físicos das terratenências; não se altera um sistema primário apenas através de um câmbio que era político, e que nunca visou sequer o processo produtivo.

Em paralelo àquilo que as fontes visigóticas definem como villulae, isto é, parcelas de exploração reduzida e sem função territorial centralizadora, outro género de núcleo concentrou em si um poder não especificado na legislação. É muito razoável considerar que a segurança regional da Tardo-Antiguidade não se construiu especialmente sobre uma súbita retracção para os castra e castella idacianos. A este respeito, a questão das villae fortificadas é um assunto polémico, documentado de forma insuficiente, mas é factual que a elite hispânica tardia 
se baseou sucessivamente em domínios rurais. Diversos episódios podem ser aduzidos como sustentação, desde a defesa da Hispânia entre 406 e 409, à enorme resistência aos exércitos de Leovigildo, já numa fase muito avançada do século VI, ou à secessão de Teudis, que contou com bucelarii oriundos das propriedades familiares rurais da sua esposa hispano-romana.

Resulta deste quadro uma reabilitação da villa que vai ressurgindo em diversas fontes visigóticas, e que continua a ter uma estrutura familiar e um propósito fundamentalmente agrícola. Inegável é a transposição do termo para uma realidade social distinta daquela que, com semelhante heterogeneidade, se adequa à do provincialismo romano clássico. O que passa a distinguir a villa visigótica é a evolução selectiva para um sistema, posto em funcionamento em época teodosiana, no qual o centro rural adquire uma autoridade que se poderia ter como pseudo-administrativa. Seria justificável, numa linha tradicional, encontrar nesta realidade uma ligação causal com o desenvolvimento de pequenas sedes religiosas semi-privadas. No entanto, fica a convicção de as paróquias rurais associadas a villae representarem, na sua origem, apenas um dos múltiplos resultados de uma condição que antes de mais era legitimada por motivos económicos. A condição subsidiada dos párocos, em liturgias privadas de uma domus ecclesiae rural, fica patente no I Concílio de Saragoça (através da proibição de celebrar reuniões ad alienas villas $\left.{ }^{(10)}\right)$, o que implica uma subordinação funcional às posses e vontades de um dominus terratenente. Esta realidade não voltaria a surgir, como problema, em época visigótica, pelo que terá sido anulado por aquela determinação episcopal, e o posterior desenvolvimento dessas paróquias serviu de catalizador alto-medieval para a intensificação de padrões de povoamento. Torre de Palma ou Montinho das Laranjeiras são dois casos muito citados de núcleos religiosos instalados em villae, que mantinham, naturalmente, uma função agrícola como actividade principal.

A proliferação coeva de fundações monásticas lusitanas foi sancionada pela monarquia ${ }^{(11)}$, numa paisagem em mutação, embora esses mosteiros mantivessem funções de exploração agrícola análogas às das grandes villae (cf. Regula communis, sobre trabalho e auto-suficiência $\left.^{(12)}\right)$, e nesse sentido não provocaram uma concepção produtiva distinta. A evolução para a villa medieval a partir da ruralidade visigótica é um caminho tortuoso e nada linear, no qual devem ser incluídas fases moçárabes com distintas forças e motivações. É por isso que, numa perspectiva cronológica visigótica, poderá ser conveniente 
matizar a intervenção eclesiástica na sobrevivência de domínios rurais, ou pelo menos negar-Ihe, enquanto força ainda pouco coerente, a relevância da sua presença em determinadas villae, por oposição a outras. Posto de outro modo, existiu uma primazia exclusivamente económica nesta configuração territorial. A ideia, originalmente avançada por Toubert, de uma dispersão de curtes, no essencial desligados entre si, tem sido posta em dúvida ${ }^{(13)}$ e reconcebida num quadro de uma maior densidade de relações. No entanto, a alternativa proposta continua a assentar numa ruptura social mais ou menos homogénea no século VI, interpretação que colide, por seu turno, com a realidade arqueológica lusitana. A par de um inegável "encastelamento" alto-medieval, e de uma autonomia ruralizante com características quase locais, algumas villae de dimensão média mantiveram funções económicas estruturantes, situando-se numa posição concorrente do grande domínio senhorial (cf. eventuais fases pós-romanas de S. Cucufate ${ }^{(14)}$ ) e da retracção de altura.

Dois sítios concretos, situados em paisagens com tradições e potencialidades agrícolas diferentes, correspondem a villae tardias, ao que tudo indica de média dimensão e com uma nítida valência pósromana. Podem ser invocados numa breve ilustração do que se acaba de escrever, de entre um conjunto mais vasto de exemplos. A escavação da villa de Santiago da Guarda, em Ansião, revelou um complexo de sofisticação insuspeitada, com um edifício baixo-medieval instalado exactamente sobre os eixos de uma villa tardia, que the serviu de fundação ${ }^{(15)}$. O sítio era conhecido acima de tudo pela epígrafe reaproveitada na torre, e referente a uma provável determinação fiscal ${ }^{(16)}$. No que importa directamente a este texto, é de apontar não apenas a fortíssima legitimação medieval do sítio, no âmbito do processo de fortificação rural na Ladeia, mas em especial a razoabilidade de ela resultar de um processo tardo-antigo continuado. Constata-se um intervalo de mais de meio milénio entre as duas grandes fases identificáveis na construção do sítio, o que em si representa um argumento abstracto bastante válido para a sua manutenção intermédia, se for tomado em conta a sobreposição praticamente total aos muros tardo-romanos. A construção da torre associa-se a níveis de ocupação claramente destruídos para o efeito, situáveis, por conseguinte, numa fase (alto-?)medieval. Adicionalmente, uma boa parte da cerâmica corresponde a formas e fabricos em utilização em Conimbriga durante a Alta Idade Média, em especial as peças com os cordões digitados aplicados em grés, culminando nas peças de corda seca(17), associadas 
a um horizonte indefinido, posterior à ocupação romana e anterior às modificações quatrocentistas.

Muito mais para Sul, no sítio da Torre Velha $1^{(18)}$, junto de Serpa, funcionou uma quinta romana de média dimensão, ou que pelo menos não parece ultrapassar a área de uma elevação relativamente pequena, embora com considerável dispersão de materiais de superfície (entre os quais vidrados islâmicos, em relação cronológica com um forno escavado numa intervenção prévia( $\left.{ }^{(19)}\right)$. Quanto aos horizontes tardo-antigos, destacam-se níveis de ocupação sequencial com formas Hayes 80B, imitações locais de Drag. 37 tardia e, significativamente, pelo menos duas formas Hayes 105, datáveis entre 580 e 660 . Sobrepõem-se a consistentes níveis com produções locais integráveis no "Grupo Sudeste» do século IX, prévio à introdução da cerâmica califal vidrada $^{(20)}$. Um dado importante reside no facto de a inteira ocupação se ter enquadrado na estrutura imperial, recorrendo a sucessivas pavimentações, e que não apontam para ocupações compartimentadas, que seriam expectáveis num contexto de desarticulação e formação de um espaço comunitário.

A quantidade de villae sofreu, confirmando um preconceito antigo, uma diminuição considerável entre o Alto Império e o século IV. De acordo com os dados disponiveis, tanto os diversos centros do território de Serpa ${ }^{(21)}$ como os de Conimbriga ${ }^{(22)}$ não apresentam sobrevivências significativas para a maioria dos casos. Nesta segunda área, o Rabaçal é um bom exemplo de uma villa sem verdadeira legitimação medieval, embora com sucessivas sobreposições residuais, o que indica presença humana mas não uma ocupação coerente, admitindo-se situações análogas no território serpense: a Herdade de D. Brites, o Monte dos Fidalgos ou Zambujeiro são apenas alguns casos imediatos com materiais romanos tardios e/ou islâmicos avulsos. Contrariamente a esta evolução descendente, pelo menos alguns dos domínios em uso no século $V$ mantiveram as suas funções agrícolas em época alto-medieval, sem necessidade de se procurar nesse facto uma relação com a implantação religiosa. Além disso, e por enquanto, ambos os exemplos invocados não revelaram indícios de estruturas de culto. Esta ausência de prova não é um argumento positivo, que de resto seria irrelevante do ponto de vista do povoamento, já que o desenvolvimento de paróquias, apesar de representar um elemento local coagulante no Ocidente ${ }^{(23)}$, resulta da realidade económica, e não o inverso. $\mathrm{O}$ que se pretende realçar aqui é uma evolução coeva e distinta dos centros de exploração agrícola entre os séculos $\mathrm{V}$ e VII, e 
em particular a operacionalidade agrária de sítios que tinham sido villae tardo-romanas, e que não perderam a sua função original antes do domínio islâmico. É claro que existem profundas diferenças entre a villa romana e as villas-herdades e villas-aldeias que surgem documentadas a partir do século $X^{(24)}$. Para o período que interessa a este texto, a menção à categoria da villa nas Etimologias de Isidoro de Sevilha (XV, 2, 10 $\left.{ }^{(25)}\right)$ não esclarece de forma inequívoca a sua natureza em relação a outros tipos de assentamento. Mas uma lei de Vitiza e Égica ${ }^{(26)}$ refere as villae num ordenamento decrescente, entre o vicus e a estalagem (diversorium), o que em nada faz supor uma fragmentação de propriedade nesses inícios do século VII, e portanto remete antes de mais para um modelo de inspiração ainda tardo-romana.

Um segundo aspecto desta continuidade prende-se com a transmissão de propriedade, ou seja, com o tipo de sucessão (familiar?) que suportou a manutenção funcional da respectiva exploração agrária. Directamente associado a este problema encontra-se o da própria extensão do ager original, e a sua evolução. Estimativas honestas nesse sentido vêem-se na obrigação de admitir graves limitações no tocante à Lusitânia imperial(27), existindo demasiadas variáveis sem controlo para determinar evoluções no território em torno de Santiago da Guarda e Torre Velha. O que por ora se pode constatar, em suma, é uma aparente manutenção visigótica na ocupação interna de ambos os sítios. Esta deu-se num ambiente selectivo, embora a grande transição na estrutura de povoamento rural se dera já em época de Teodósio e da sua dinastia, em definitivo detrimento do padrão de lógica alto-imperial. Uma importante função adicional destes núcleos prendese com a sua inserção na bem documentada rede anonária visigótica, e poderiam, aliás, carecer de algumas valências residenciais ${ }^{(28)}$ que se associam aos seus precursores imperiais. É de resto muito possível que um factor central no fim das villae seja de encontrar nesta promiscuidade de época visigótica avançada, e no incremento das responsabilidades de recolha fiscal centrada em núcleos familiares rurais, desse modo subvertendo o enquadramento latifundiário romano, e em última instância abrindo caminho para a desagregação de propriedade. Os dois exemplos aduzidos são interpretáveis nesta óptica, independentemente do tipo de ocupação medieval que Ihes foi, por fim, sobreposta. Em boa verdade, as reconversões islâmicas de antigas villae não foram raras, mas ao que tudo indica correspondem a estruturas já identificáveis, por conveniência metodológica, como alcarias. 


\section{Notas}

(1) B. WARD-PERKINS, A queda de Roma e o fim da civilização, Lisboa, 2006, 31-49.

(2) P. KOSSO, Epistemic Independence between Textual and Material Evidence. Methods in the Mediterranean, Historical and Archaeological Views on Texts and Archaeology, Leiden, 1994, 191194.

(3) A. A. FERNANDES, Paróquias Suevas e Dioceses Visigóticas, sep. Arquivo do Alto Minho 14-16, 1968, 99 e 109.

(4) T. F. GLICK, From Muslim fortress to Christian castle, Manchester 1995, 10.

(5) Vide P. REYNOLDS, Trade in the Western Mediterranean, AD 400-700: The ceramic evidence, Oxford, 1995.

(6) A. MARCONE, "A long Late Antiquity? Considerations on a controversial periodization", Journal of Late Antiquity 1/1, 2008, 8.

(7) W. A. GOFFART, Barbarian tides: the migration age and the later Roman Empire, Philadephia, 2006, 152.

(8) R. B. HITCHNER, Historical Text and Archaeological Context in Roman North Africa: The Albertini Tablets and Kasserine Survey. Methods in the Mediterranean, Historical and Archaeological Views on Texts and Archaeology, Leiden, 1994, 134-138.

(9) S. RAVEN, Rome in Africa, London, 1993, 200-202.

(10) J. VIVES, Concilios Visigoticos e Hispano-romanos, Barcelona/Madrid, 1963, 16.

(11) L. GARCÍA MORENO, «El habitat rural disperso en la Península Ibérica durante la Antigüedad Tardía (Siglos V-VII)", in Arte, sociedad, economía y religión durante el Bajo Imperio y la Antigüedad Tardia, Antigüedad y Cristianismo VIII, Murcia, 1991, 266.

(12) T. GONZÁLEZ, La Iglesia desde la conversión de Recaredo hasta la invasión arabe, Madrid, 1979, 649-650.

(13) R. FRANCOVICH, R. HODGES, Villa to village, London, 2003, 76-77.

(14) S. da PONTE, "Artefactos romanos e post-romanos de S. Cucufate", Conimbriga 26, $1987,159-162$.

(15) L. CORTESÃO, R. PEREIRA, L. TRINDADE, "Um sedimento, uma ruína, um projecto. O Paço dos Vasconcelos, em Santiago da Guarda", Monumentos 25, 2006, 214-225.

(16) J. d'ENCARNAÇÃO, A. J. N. MONTEIRO, «A propósito de uma inscrição latina em Santiago da Guarda (Ansião)", Conimbriga 32/33, 1993-94, 303-311.

(17) R. M. PEREIRA, “Intervenção Arqueológica no Paço dos Vasconcelos", in Relatório de Progresso Técnico-Científico II, IASG 2003, Ansião, 2004, 181-182.

(18) Sítio recentemente intervencionado (Palimpsesto/EDIA), e sobre o qual se prepara uma publicação de conjunto.

(19) Informação pessoal de Teresa Ricou Nunes da Ponte.

(20) C.E.V.P.P., «Ceramicas de epoca visigoda en la Peninsula Iberica. Precedentes y perduraciones", in IV Congresso Internacional A cerâmica medieval no Mediterrâneo Ocidental, Mértola, 1991, 52.

(21) P. CARVAlho, S. GoMeS, M. C. LOPES, Arqueologia do Concelho de Serpa, Serpa, 1998. 
(22) M. PESSOA, "Subsídios para a carta arqueológica do período romano na área de Conimbriga", Conimbriga 25, 1986, 53-73.

(23) M. VALENTI, “La Toscana tra VI e IX Secolo. Città e Campagna tra fine dell'Età Tardoantica ed Altomedievo", in G. P. Brogiolo, cur., La fine delle ville romane: trasformazioni nelle campagne tra tarda antichità e alto Medioevo, Atti del I convegno archeologico del Garda, Mantova, 1998, 102.

(24) J. de ALARCÃO, "In territorio Colimbrie: lugares velhos (e alguns deles, deslembrados) do Mondego", Trabalhos de Arqueologia 38, 2004, 17.

(25) J. OROZ RETA, M. A. MARCOS CASQUERO, San Isidoro de Sevilla, Etimologias II (libros XI-XX), Madrid, 1994, 229.

(26) L. GARCÍA MORENO, Historia de España Visigoda, Madrid, 1989, 263.

(27) M. M. LANGLEY, "Est in agris: a spatial analysis of Roman uillae in the region of Monforte, Alto Alentejo, Portugal", Revista Portuguesa de Arqueologia 9/2, 2006, 325.

(28) V. H. CORREIA, A. DE MAN, R. PEREIRA, "Dinâmicas urbanas e rurais nas Terras de Sicó: alguns estudos de caso para a elaboração de um projecto" in Simpósio Ibero-americano Património geológico, arqueológico e mineiro em regiões cársicas, Batalha, 2008, 234-235. 